\title{
WAVE RUNUP PREDICTION FOR FLOOD MAPPING
}

\author{
Jeffrey A. Melby ${ }^{1}$, Norberto C. Nadal-Caraballo ${ }^{1}$ and Nobuhisa Kobayashi ${ }^{2}$
}

\begin{abstract}
Wave runup determines the extent over which waves act. Wave runup is therefore an important parameter to determine flood inundation extents from coastal storms. Cross-shore and longshore sediment transport are a function of the hydrodynamics on the beach and are therefore related to wave runup. Several benchmark wave runup data sets are summarized and used to evaluate the available tools for predicting wave runup for flood hazard assessment. Benchmark data span a range of shoreline conditions including sandy beaches on the Pacific and Atlantic coasts, dissipative to reflective beaches, as well as structures ranging from impermeable smooth levees to rough permeable rubble mounds. Data include laboratory and prototype measurements. Tools for predicting wave runup are analyzed including empirical equations, computer programs based on empirical equations, and the CSHORE time-averaged cross-shore model. Most of the tools show fairly high degrees of skill but some do not. The study recommends using CSHORE to model runup for most beach and structure conditions. However, CSHORE is not likely to predict wave runup on infragravity-dominated dissipative beaches well. For these cases, it is recommended that one of the recommended empirical equations for beaches be used.
\end{abstract}

Keywords: wave runup; wave setup; flood mapping; coastal flood; CSHORE

\section{INTRODUCTION}

Wave runup prediction is required on most coastal engineering projects. Wave runup computation is in a state of transition due to recent detailed and accurate field and laboratory measurements and introduction of new computational tools. In this paper we review and compare some of the more attractive new methods for computing wave runup by comparing to benchmark data sets.

In the U.S.A., flood mapping is done by FEMA (Federal Emergency Management Administration) within Flood Insurance Studies (FIS) to establish the 1\% annual exceedance probability inundation extent or base flood elevation (BFE). This mapping supports insurance requirements for flood prone areas. More recent FEMA guidelines suggest computing wave and water level conditions for all significant historical storms using high-fidelity regional wave and surge numerical models (e.g. Melby et al. 2012). Runup limits are computed along transects and the BFE computed. For FEMA FIS, runup has been determined using empirical equations as found in the Shore Protection Manual (USACE 1984) or the Coastal Engineering Manual (2002), or it has been computed using computer programs, like Automated Coastal Engineering System (ACES) or Runup 2.0, which are based on empirical equations. Most of these equations were derived from experiments measuring runup on steep slopes. Both ACES and Runup 2.0 compute runup with empirical equations mostly on regular wave tests. Empirical equations are limited to the conditions tested.

Recent studies by van Gent (2001), Stockdon et al. (2006) and others provide more generalized guidance on runup for both structures and beaches. In addition, recently developed numerical models, including CSHORE and BOUSS1D, provide high fidelity and efficient computation of runup and setup and are now being introduced into flood mapping studies. In this paper we compare the predictions of various empirical equations to a number of structure and beach benchmark data sets. In addition, we compare predictions from Runup 2.0 and CSHORE programs to the benchmark data sets.

\section{WAVE RUNUP OVERVIEW}

Wave runup, $R$, is specifically defined as the landward extent of wave uprush measured vertically from the still water level (SWL). Wave runup consists of two parts: wave setup which is a mean (averaged over time) water surface elevation and swash (Figure 1). Swash, $S$, is the variation of the water-land interface about the mean. So wave runup is often referred to using the following equation (e.g., Stockdon et al. 2006):

$$
R=\bar{\eta}_{\max }+\frac{S}{2}
$$

where the maximum mean setup, $\bar{\eta}_{\max }$, is the superelevation of the mean water level at the shoreline.

\footnotetext{
${ }^{1}$ US Army Engineer Research and Development Center, Vicksburg, MS, 39180, USA, Fax: 601-634-3433, Jeffrey.A.Melby@usace.army.mil, Norberto.C.Nadal-Caraballo@usace.army.mil

${ }^{2}$ Center for Applied Coastal Research, University of Delaware, Newark, DE 19716, USA, Fax 301-831-1228, nk@udel.edu
} 


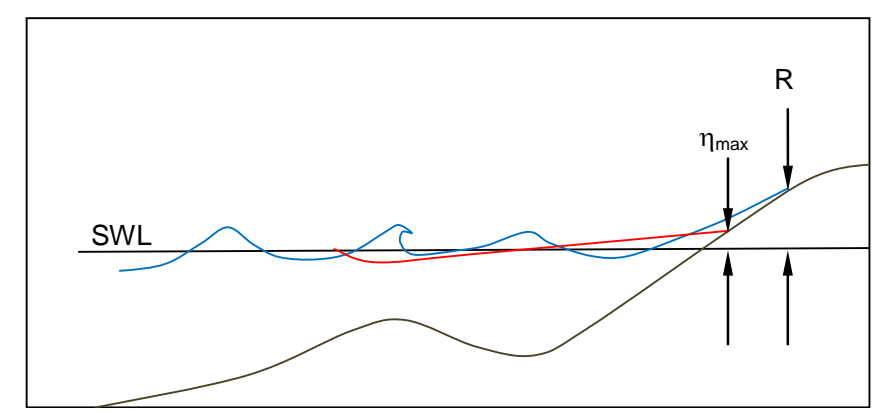

Figure 1. Conceptual sketch of wave runup on a beach (blue line) and setup (red shorter line)

Wave setup is a result of the momentum transfer of the radiation stress cross-shore gradient due to breaking waves, and consists of a mean and an oscillating component (Longuet-Higgins and Stewart 1962, 1964). Setup varies across the surf zone, being slightly negative at the wave break point and increasing to a maximum above the still water level. Often, setup is described by a mean component with the time varying components of setup and swash both considered as runup as per Kobayashi (1999). Wave setup variation occurs at periods on the order of $100 \mathrm{sec}$ on natural beaches. For U.S. Pacific Coast conditions where the wave spectra can be narrow, the slowly oscillating component of setup may be the dominant portion of runup.

Wave runup has been studied extensively over the last half century. Recent summary works include Kobayashi (1999), the Coastal Engineering Manual (2002), and the EurOtop Manual (2007). Wave runup on coastal structures can be subdivided into impermeable core (levees and revetments), permeable core (rubble mound breakwaters), smooth (grass covered levees or planar slopes in the laboratory) and rough (stone or concrete armored structures), and complex or uniform slopes. Beaches, on the other hand, are characterized by shallower average slopes of 1:100 - 1:10. Beach morphology changes with time with beach steepening during storms when sediment and the nearshore bar move offshore. So defining a single average slope for a beach, to estimate runup, can be uncertain. Steeper beaches are wave-reflecting while shallower-sloping beaches are wave-dissipating.

Battjes (1974a, b) classified wave breaking according to the surf similarity or Iribarren parameter $\xi=\tan \alpha /(H / L)$ (Iribarren and Nogales 1949), where $\alpha$ is the nearshore slope from horizontal, $H$ is the incident wave height, and $L$ is the incident wave length. Battjes noted that spilling breakers correspond to $\xi<0.5$, plunging breakers to $0.5<\xi<3.3$ and surging or collapsing breakers occur for $\xi>3.3$. Madsen et al. (1997a, b) found that $\xi$ also governed the type of shoreline motion. They noted that individual swash oscillations are distinct for breakers of the plunging to surging type $(\xi>0.5)$ but that wave group-induced sub-harmonic motion dominates the swash oscillations for breakers of the spilling type ( $\xi<0.5$ ). They also described the influence of bound long waves (wave grouping, e.g., Jiabao 1993). Low frequency incident waves from bound long waves and slow time variations of the breaker location generate both bound and free long waves in the surf zone creating what is known as surf beat or slow variations of the shoreline. Incident short waves are mostly dissipated in the surf zone while free long waves are almost entirely reflected.

Mase and Iwagaki (1984) and Mase (1989) summarized the impact of wave groupiness on wave runup. They noted that for steep structures, increasing wave groupiness yields higher runup. Conversely, for shallow slopes, wave groupiness variability has little effect on runup. Runup at infragravity wave frequencies is commonly defined for frequencies lower than $f=0.05 \mathrm{~Hz}$ (e.g., Guza and Thornton 1982). They note that the progressive wave component of runup is saturated so that the infragravity component can constitute virtually all of the variance in the runup. Holland and Holman (1999) also describe cross-shore standing waves or edge waves resulting from the almost complete reflection of infragravity waves.

Nielsen and Hanslow (1991) suggested that the Rayleigh distribution is reasonable for runup on beaches. Kobayashi (1997) summarized several studies that showed runup on structures to be approximately Rayleigh distributed.

Hunt (1959) suggested that relative runup is proportional to the surf similarity parameter or Iribarren number:

$$
\frac{R}{H_{0}}=\xi_{0}
$$


where $H_{0}$ is the average deep water regular wave height and $T$ the regular wave period. This simple expression states that wave runup increases with increasing shore steepness and decreasing wave steepness. In the following sections, we discuss this relation as it has been carried forward in present day design equations.

\section{WAVE RUNUP DATA}

In this section, a number of small scale laboratory and full scale prototype wave runup data sets assembled for this study are summarized. The data sets are listed and discussed in more detail in Melby (2012).

Mase and Iwagaki (1984) and Mase (1989) conducted laboratory experiments of smooth uniform slopes ranging from 1:30 to 1:5. Irregular waves were measured on the flat portion of the flume in intermediate depth. Swash was measured at the level of the slope in a channel using a capacitance wire gage. The runup gage channel was $1 \mathrm{~cm}$ deep and $3 \mathrm{~cm}$ wide. Runup statistics were computed by dividing the number of runups by the number of incident waves and then rank ordering the result. Runup included setup. The small-scale model experiment was not to any specific scale as it was a generalized model. This data set is limited to the following ranges: 120 total tests, 30 per slope, 4 smooth impermeable uniform slopes; Spectrum Type: Pierson-Moskowitz; Spectral Groupiness Factors: 0.74 and 0.53; Offshore Bathymetry: flat.

Van der Meer (1988) and Van der Meer and Stam (1992) summarized generalized irregular wave laboratory experiments on a variety of permeable and impermeable rock-armored coastal structures. The experiments were generalized and so not scaled to any specific structure. The related studies of de Waal and van der Meer (1992) and van der Meer and Stam (1992) generated empirical runup equations in the Coastal Engineering Manual (2002) and the Dutch Wave Runup and Wave Overtopping at Dikes Manual (TAW 2002). They give significant wave height as a time domain parameter $H_{1 / 3}$. These data correspond to structures where the toe is in relatively deep water $\left(h_{t}>3 H_{1 / 3}\right)$ with no surf zone seaward of the structure; where $h_{t}$ is the toe depth. Therefore, $H_{1 / 3}$ can be set equal to $H_{m 0}$ for these data with very little error. The data set is limited to the following ranges of parameters: Irregular waves on rubble mound structures with uniform slopes; Spectrum Type: Pierson-Moskowitz; Offshore Bathymetry slope: flat.

Van Gent (1999a, b; 2001) conducted laboratory and prototype experiments of relatively smooth uniform and bermed impermeable dike slopes. The experiment consisted of two parts: a) full-scale measurements from the Petten Sea Defense site with associated small scale physical model experiment (Series P); and b) generalized small scale model experiments with systematic variation of parameters (Series A - C). Series P is reported in van Gent (1999a). Series A - C are reported in van Gent (1999b, 2001). The small-scale model study was conducted using undistorted geometry at a length scale of 1:40. Irregular waves were measured on the flat portion of the flume in intermediate depth and across the shallow surf zone to the structure toe. Swash was measured using a step gage at an elevation of 2.5 $\mathrm{mm}$ above the slope. The probes were spaced at $25 \mathrm{~mm}$. In addition, a continuous runup gage was placed parallel to the slope at an elevation of $5 \mathrm{~mm}$ above the slope. Runup was computed by dividing the number of runups by the number of incident waves and then rank-ordering the result. These data are limited to the following ranges of parameters: Spectrum Type: single peaked and double peaked JONSWAP; Spectral Groupiness Factors: varied; Offshore Bathymetry: flat for lab.

Additional coastal structure runup data were obtained from van der $\mathrm{Meer}^{3}$ based mostly on large scale tests conducted in various flumes. These data are described in EurOtop (2007).

Stockdon et al. (2006) reported a large beach runup data set consisting of data from nine full scale experiments conducted between 1982 and 1996. The foreshore beach slope $\beta_{f}$ was defined as the average slope over a region between $\pm 2 \sigma$ of the mean water level, where $\sigma$ was defined as the standard deviation of the continuous water level record. In this case, the wave conditions are given in deep water computed by deshoaling waves from a depth of about $8 \mathrm{~m}$ using linear wave theory. Most of the measurements were made using shoreline tracking from video. Runup $R_{2 \%}$ was computed by rank ordering the runups and dividing by the total number of runups. This can be contrasted with the data sets for structures where the runups were divided by the total number of incident waves. There are typically fewer runups than incident waves so Stockdon's resulting runup statistic will be relatively greater. Another thing to note is that for structure experiments, the wave conditions mostly correspond to those of storms while those of beaches correspond to non-storm conditions for most open coast locations. The impact of measuring non-storm conditions is primarily in the proportion of infragravity

\footnotetext{
${ }^{3}$ Personal communication.
} 
wave energy and beach slope. It is expected that during storm conditions, incident wave energy will typically dominate the runup response whereas in non-storm conditions, it is possible for infragravity energy to dominate. Beach slope typically steepens during storms, accentuating the impact of incident waves on runup. The beach profiles used to describe these data are average profiles, averaged in time but approximately corresponding to the beach profile at the location of the runup measurement.

RUNUP EMPIRICAL FORMULAE

Battjes (1974a) extended the regular wave Hunt (1959) formula to irregular waves using time domain wave parameters. His formula for relative runup was as follows:

$$
\frac{R_{2 \%}}{H_{1 / 3}}=C_{m} \xi_{0 m} \quad \xi_{0 m}=\frac{\tan \alpha}{\sqrt{s_{0 m}}} \quad s_{0 m}=\frac{H_{s}}{L_{0 m}} \quad L_{0 m}=\frac{g T_{m}^{2}}{2 \pi}
$$

with $C_{m}=1.49-1.87$ and where $\alpha$ is the structure slope from horizontal, and $T_{m}$ is the mean wave period. Other authors have expanded the range of $C_{m}$. Ahrens (1981) gave a variation of Equation 3 for a range of structure slopes from 1:1 to 1:4 using frequency domain wave parameters. Ahrens expressed the surf similarity parameter where $\xi_{0 p}=\tan \alpha / \sqrt{s_{0 p}}$, where $s_{0 \mathrm{p}}=H_{m 0} / \mathrm{L}_{0 p}, L_{0 p}=g T_{p}{ }^{2} / 2 \pi$ and $T_{p}$ is the peak wave period. His coefficient was $C=1.6$, roughly in the middle of the range given by Battjes.

A more generalized form of Hunt's equation was proposed by Holman (1986) for beach data

$$
\frac{R_{2 \%}}{H_{m 0}}=a \xi_{0 p}^{b}+c
$$

Hunt's data suggested that $a=1, b=1$, and $c=0$ using deep water regular waves. Holman (1986) fit this equation with $a=0.83, b=1$, and $c=0.2$ to field data from Duck, NC, using the intermediate depth $H_{m 0}$ and $T_{p}$. Mase (1989) developed a predictive equation for irregular wave runup on plane impermeable slopes, based on the laboratory data summarized above. Equation 4 was modified with $a=1.86, b=0.71$ and $c=0$ using wave parameters from deep water. Figure 2 shows the fit of the Mase equation to Mase data. Similar to the Holman equation, there is very good fit to the roughly linear portion where $\xi_{0 p}<2$ but deviation for cases with higher $\xi_{0 p}$ with steeper slopes or lower steepness waves.

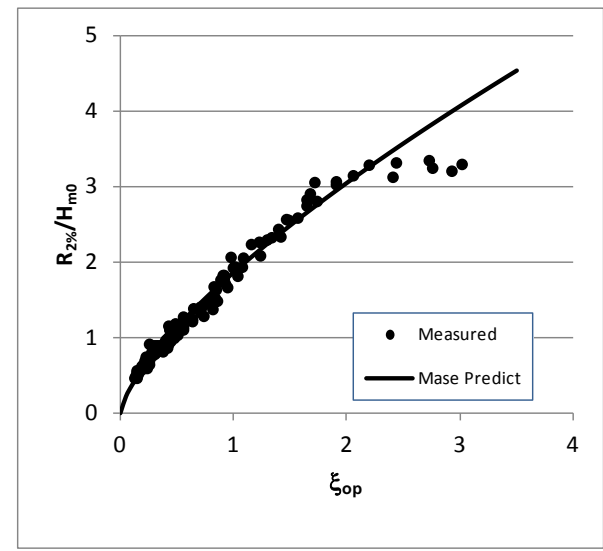

Figure 2. Mase relative runup prediction plotted with Mase measurements.

Van der Meer and Stam (1992), analyzed wave runup on rock-armored structures for a range of spectral shapes. Their recommended runup guidance, an extension of Equation 3, was given as:

$$
\frac{R_{2 \%}}{\gamma H_{1 / 3}}=A \xi_{0 m} \quad \xi_{0 m} \leq 1.5, \quad \frac{R_{2 \%}}{\gamma H_{1 / 3}}=B \xi_{0 m}^{C} \quad \xi_{0 m} \geq 1.5, \quad \frac{R_{2 \%}}{\gamma H_{1 / 3}} \leq 3
$$

where $A=0.96, B=1.17$, and $C=0.46$. An influence factor $\gamma$ is used to account for various things as described below. The upper limit of relative runup was introduced for permeable-core structures. Equations 3-5 all use wave parameters defined in intermediate to deep water resulting in wave conditions that conform to the Rayleigh wave height distribution. As such, $H_{1 / 3}$ can be interchanged with $H_{m 0}$ in Equations 3 and 5. However, these equations are not necessarily valid in shallow water where there is a wide surf zone. 
Equation 5 is plotted in Figure 3 against the van der Meer and Stam data. The equation fits the range of surf parameters from the linear range, through the transition area, and into the surging region. However, the scatter is increasing in the surging region where the fit is less certain.
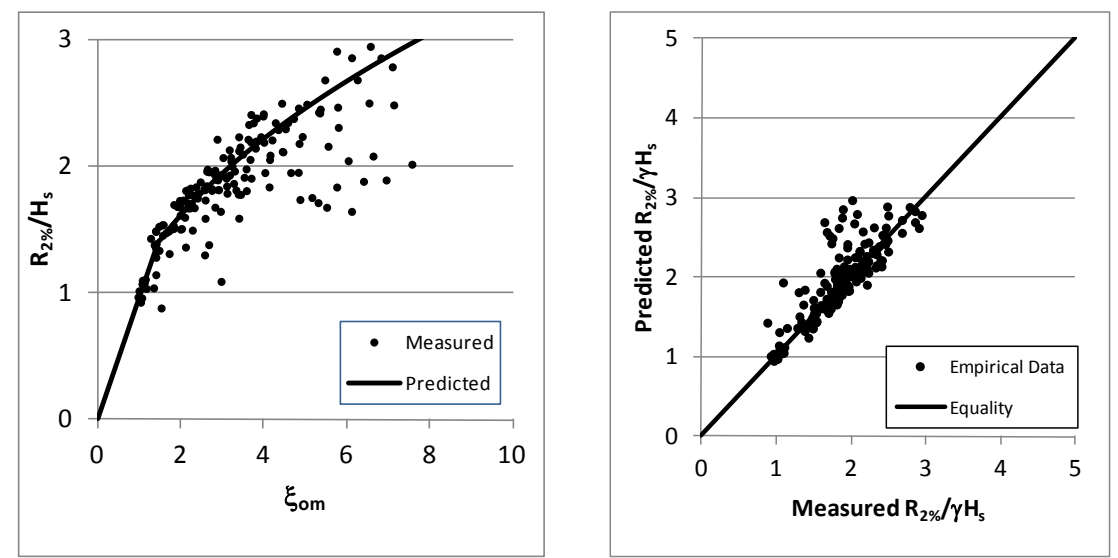

Figure 3. Van der Meer and Stam relative runup prediction using Equation 5.

Battjes (1974a) gave runup influence factors that reduce the estimated runup for various structure armor and cross section types. In Equation 3, $H_{s}$ is replaced by $\gamma H_{s}$, where, for example, $\gamma=0.55$ for multi-layer stone armor. The influence factors were republished in the Shore Protection Manual (USACE 1984). Empirical coefficient $A=0.96$ in Equation 5 for runup on rock structures due to plunging breakers is roughly 50 percent of the value of $A=1.86$ in the Mase equation for smooth structures, confirming Battjes factor for rock structures for $\xi_{0 p}<2$. De Waal and van der Meer (1992) gave an update of influence factors where the total influence factor is the product of component influence factors $\gamma=\gamma_{b} \gamma_{f} \gamma_{h} \gamma_{\beta}$ and the various factors are for berms $\left(\gamma_{b}\right)$, slope roughness $\left(\gamma_{f}\right)$, shallow water $\left(\gamma_{h}\right)$, and angle of wave attack $\left(\gamma_{\beta}\right)$.

Recently, the Hunt equation was extended by van Gent (1999a, b; 2001) to shallow water where wave heights deviate from the Rayleigh distribution. Van Gent (2001) gave equations to fit his runup data for smooth and rough impermeable structures with varied uniform and compound slopes. The primary best-fit equation is:

$$
\frac{R_{2 \%}}{\gamma H_{s}}= \begin{cases}c_{0} \xi & \xi \leq p \\ c_{1}-c_{2} / \xi & \xi>p\end{cases}
$$

where $c_{2}=0.25\left(c_{1}\right)^{2} / c_{0}, p=0.5 c_{1} / c_{0}$, and $c_{0}$ and $c_{1}$ are given for different wave period statistics. The optimal fits were for $T_{p}$ and $T_{m-1,0}$, where $T_{m-1,0}=m_{-1} / m_{0}$ is the negative first moment wave period of the wave variance density spectrum and $m_{n}=\int_{0}^{\infty} f^{n} S(f) d f$. Typically, $T_{m-1,0} \approx T_{p} / 1.1$. The fit coefficients were given as: $T_{p}: c_{0}=1.35, c_{1}=4.3, c_{2}=3.4, p=1.6 ; T_{m-1,0}: c_{0}=1.35, c_{1}=4.7, c_{2}=4.1, p=1.7$. Although not widely available, $T_{m-1,0}$ provides a more stable parameter than $T_{p}$ because it is based on the integrated wave variance density spectrum rather than the somewhat uncertain peak of the spectrum. In Equation 6, $\gamma=\gamma_{f} \gamma_{\beta}$ is a cumulative adjustment for slope roughness $\left(\gamma_{f}\right)$ and wave directionality $\left(\gamma_{\beta}\right)$. Van Gent dropped $\gamma_{\mathrm{h}}$ and $\gamma_{\mathrm{b}}$ suggesting that these coefficients are not required. Van Gent incorporated the depth effects into Equation 6 and the berm effect into the slope in the surf similarity parameter. For a berm, van Gent suggests using an average structure slope of $\tan \alpha=4 H_{s} / L$, where $L$ is the horizontal distance between points on the structure at $2 H_{s}$ below, and $2 H_{s}$ above, the still water line. Roughness reduction factors are 1.0 for smooth slopes, 0.9 for grass-covered slopes, 0.6 for single layer rock slopes and 0.5 for multi-layer rock slopes. The wave directionality factor is given as $\gamma_{\beta}=1-0.0022 \beta$ for $\beta<80$ deg where $\beta$ is the wave angle from shore normal. Equation 6 is plotted versus Van Gent's data in Figure 4. 


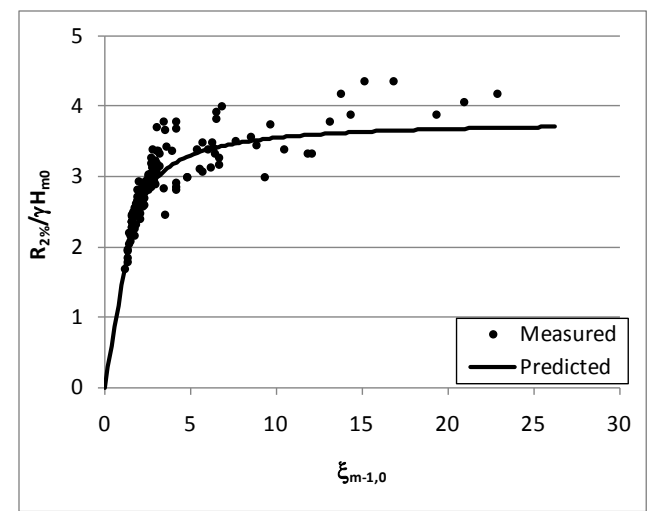

Figure 4. Equation 6 relative runup prediction plotted with van Gent measurements.

The TAW (2002) manual has been updated in the EurOtop (2007) manual to include more recent experimental results. The EurOtop runup equation is given in Equation 7 and plotted in Figure 5 with the van der Meer and Stam data. A value of $\gamma_{f}=0.55$ was applied to account for roughness of multilayer rock armor. In addition, the approximation $T_{p}=1.1 T_{m-1,0}$ was used. The fit to the data appears to be reasonable in Figure 5 with a modest overprediction bias. The modification from the TAW equation to the EurOtop is to decrease the coefficient on the first equation from 1.75 to 1.65 , the two coefficients in the second equation from 4.3 and 1.6 to 4.0 and 1.5 and change the wave period statistic. This modification represents roughly a 14\% decrease in predicted runup. Figure 6 shows the EurOtop equation plotted with additional large scale data referenced in the EurOtop manual. The summary data were provided to the author by van der Meer (2012) and are shown here for completeness.

$$
\frac{R_{2 \%}}{H_{m 0}}=1.65 \gamma_{b} \gamma_{f} \gamma_{\beta} \xi_{m-1,0} \quad \frac{R_{2 \%}}{H_{m 0}} \leq \gamma_{b} \gamma_{f \text { surging }} \gamma_{\beta}\left(4-1.5 / \sqrt{\xi_{m-1,0}}\right)
$$

where $\gamma_{f \text { surging }}=\gamma_{f}+\left(\xi_{m-1,0}-1.8\right)\left(1-\gamma_{f}\right) / 8.2$ and $\gamma_{f \text { surging }}=1.0$ for $\xi_{m-1,0}>10$.

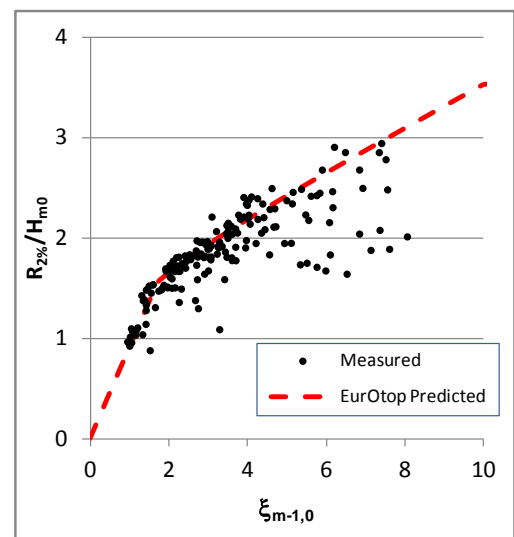

Figure 5. EurOtop runup prediction plotted with van der Meer and Stam measurements.

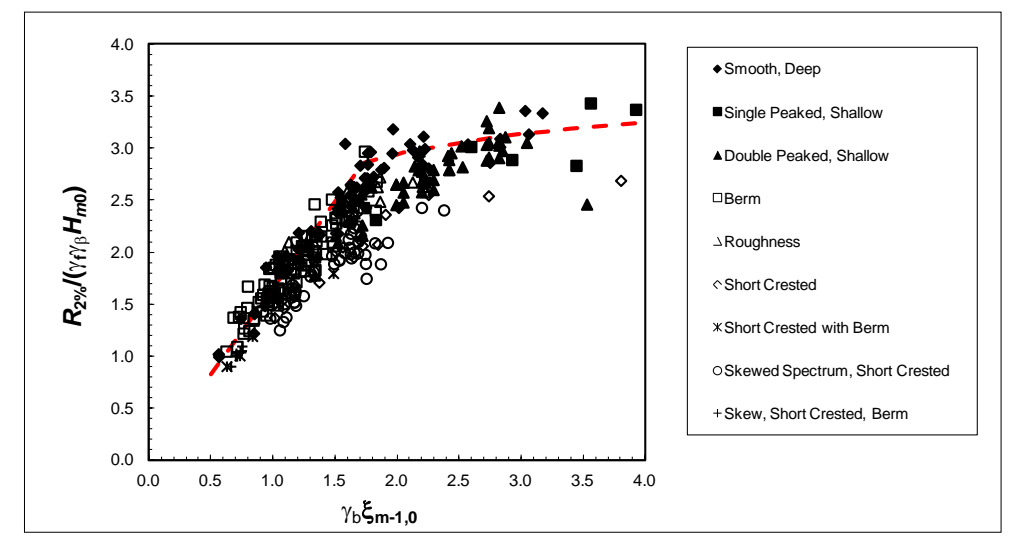

Figure 6. EurOtop runup prediction plotted with large scale measurements. 
In Figure 6, a wide variety of structure and wave and water level conditions are represented including shallow and deep water at the structure toe, single peaked and double peaked spectra, shortcrested and long crested seas, skewed spectra, smooth impermeable and rubble structures, varied roughness, and bermed structures. As shown in Figure 6, the EurOtop equation fit appears to be reasonable with a small overprediction bias.

In conclusion, runup is reasonably well predicted for structures using the Hunt-type equation with variations that account for the reduced influence of the surf similarity parameter for steep structures and low steepness waves as well as the many variations of structure and wave spectra conditions.

\section{Analysis of runup prediction for structures}

Statistical measures given below are utilized to describe the skill of the various runup models. For these relations, $R M S$ = root mean square, $p=$ predicted, $m=$ measured, and $n=$ number of data points.

Dimensional RMS Error:

Non-dimensional RMS Error:

Bias:

Standard Deviation of Errors:

Scatter Index:

Normalized RMS Error Performance:

Normalized Bias Error Performance:

Normalized SI Performance:

Summary Performance Score:
Mean of Measurements:

$$
\begin{aligned}
& E_{r m s}=\sqrt{\frac{1}{n} \sum_{i=1}^{n}\left(p_{i}-m_{i}\right)^{2}} \\
& e_{r m s}=\sqrt{\frac{1}{n} \sum_{i=1}^{n}\left(\frac{p_{i}}{m_{i}}-1\right)^{2}} \\
& B=\frac{1}{n} \sum_{i=1}^{n}\left(p_{i}-m_{i}\right) \\
& \sigma_{d}=\sqrt{\frac{1}{n-1} \sum_{i=1}^{n}\left(p_{i}-m_{i}-b\right)^{2}} \\
& \bar{m}=\frac{1}{n} \sum_{i=1}^{n} m_{i} \\
& S I=\frac{\sigma_{d}}{\bar{m}} \\
& \hat{E}_{r m s}=\left(1-\frac{E_{r m s}}{m_{r m s}}\right) \\
& \hat{b}=\left(1-\frac{|B|}{m_{r m s}}\right) \\
& \widehat{S I}=(1-S I) \\
& P_{S}=\frac{\hat{E}_{r m s}+\hat{b}+\widehat{S I}}{3}
\end{aligned}
$$

\begin{tabular}{|c|c|c|c|}
\hline & $\begin{array}{c}\text { Van der } \\
\text { Meer and } \\
\text { Stam (Eq. 5) }\end{array}$ & $\begin{array}{l}\text { Van Gent } \\
\text { (Eq. 6) }\end{array}$ & $\begin{array}{c}\text { EurOtop } \\
\text { (Eq. 7) }\end{array}$ \\
\hline Dimensional RMS Error (cm) & 3.4 & 3.1 & 3.7 \\
\hline Bias (cm) & 0.01 & -0.01 & 0.01 \\
\hline Nondimensional RMS Error & 0.17 & 0.14 & 0.18 \\
\hline Standard Deviation of Errors (cm) & 3.1 & 2.7 & 3.4 \\
\hline Scatter Index & 0.15 & 0.12 & 0.16 \\
\hline Normalized RMS Error Performance & 0.85 & 0.86 & 0.83 \\
\hline Normalized Bias Performance & 0.95 & 0.94 & 0.94 \\
\hline Normalized SI Performance & 0.85 & 0.88 & 0.84 \\
\hline Summary Performance & 0.88 & 0.89 & 0.87 \\
\hline
\end{tabular}

These statistical skill measures were computed for the varied structure empirical models against the structure data sets of van der Meer and Stam and van Gent. The results are summarized in Table 1. Generally, the models have relatively high skill. The EurOtop equation is the most accurate and versatile, fitting all data well. The EurOtop and van Gent equations also make use of previously published guidance in the CEM and TAW manual for influence coefficients but give somewhat simpler application.

Stockdon et al. (2006) developed empirical relations based on data from nine field experiments. They differentiate the beaches as dissipative or reflective depending on the surf similarity parameter. Dissipative beaches are defined for $\xi_{0 p}<0.3$ and reflective beaches for $\xi_{0 p}>1.25$. They characterize runup as the sum of wave setup and swash and decompose swash into the sum of incident and infragravity contributions. The separation of swash spectral energy is as follows: $f>0.05 \mathrm{~Hz}$ for 
incident wave energy and $f<0.05 \mathrm{~Hz}$ for infragravity. The time varying beach profile is averaged over the duration of an experiment. They recommend a universal beach runup formula as:

$$
R_{2 \%}=1.1\left(0.35 \beta_{f}\left(H_{m 0} L_{0 p}\right)^{1 / 2}+\frac{1}{2}\left[H_{m 0} L_{0 p}\left(0.563 \beta_{f}^{2}+0.004\right)\right]^{1 / 2}\right)
$$

where the first term in the brackets represents wave setup contributions, the $\beta_{f}^{2}$ term is for incident wave contributions, and the 0.004 term is for infragravity contributions. For dissipative beaches with very shallow slopes, the equation reduces to infragravity-dominated runup:

$$
R_{2 \%}=0.043\left(H_{m 0} L_{0 p}\right)^{1 / 2} \quad \xi_{0 p}<0.3
$$

As reported by Melby (2012), the incident-wave-dominated sites are all except Scripps, Agate, and Terschelling. Agate and Terschelling are infragravity-dominated. Scripps is generally infragravitydominated. Stockdon relations predict that setup and swash are of similar relative magnitude with swash contributing about 43 percent more for the incident-wave-dominated sites. For infragravitydominated sites, the swash dominates over setup and infragravity energy is the major contributor to wave runup.

Equation 18 is plotted in Figure 7 with the measured beach runup data. The skill of Equation 18 was evaluated and the results are summarized in Table 2. The best fits of the Hunt-based Holman and modified Mase formulae for the beach data are also evaluated in Table 2. The varied predictive equations provide similar skill.

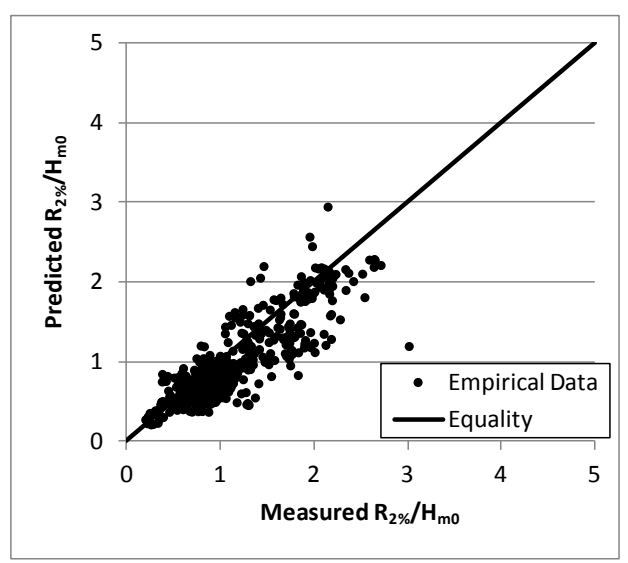

Figure 7. Fit of Stockdon equations to Stockdon beach data.

\begin{tabular}{|l|c|c|c|}
\hline Table 2. Error statistics and skill scores for empirical equations compared to beach data \\
\hline & $\begin{array}{c}\text { Holman }^{1} \\
\text { (Eq. 4) }\end{array}$ & $\begin{array}{c}\text { Stockdon } \\
\text { (Eq. 18) }\end{array}$ & $\begin{array}{c}\text { Mase }^{2} \\
\text { Eq. 4) }^{2}\end{array}$ \\
\hline Dimensional RMS Error (m) & 0.36 & 0.38 & 0.37 \\
\hline Bias (m) & 0.00 & -0.17 & 0.00 \\
\hline Nondimensional RMS Error & 0.30 & 0.27 & 0.28 \\
\hline Standard Deviation of Errors (m) & 0.11 & 0.34 & 0.37 \\
\hline Scatter Index & 0.25 & 0.23 & 0.26 \\
\hline Normalized RMS Error Performance & 0.77 & 0.76 & 0.76 \\
\hline Normalized Bias Performance & 1.00 & 0.89 & 1.00 \\
\hline Normalized SI Performance & 0.75 & 0.77 & 0.74 \\
\hline Summary Performance & 0.84 & 0.80 & 0.84 \\
\hline 1 Equation 4 with fit coefficients $\mathrm{a}=0.90, \mathrm{~b}=1.0, \mathrm{c}=0.25$ & \\
2 Equation 4 with fit coefficients $\mathrm{a}=1.10, \mathrm{~b}=0.70, \mathrm{c}=0.0$ & \\
\hline
\end{tabular}

\section{COMPUTER PROGRAMS BASED ON EMPIRICAL EQUATIONS}

Leenknecht et al. (1995) summarized models used for wave runup in the Automated Coastal Engineering System (ACES). The Mase (1989) relation for runup on gently sloping smooth planar slopes was included for beaches but the details of application were left as user inputs (beach slope, fit coefficient). For runup on coastal structures, the relations of Ahrens and Titus (1985) are recommended 
for smooth impermeable slopes, and Ahrens and McCartney (1975) for rough slopes (riprap). These relations are based on regular wave experiments. The runup relation for rough slopes was given as:

$$
\frac{R}{H}=\frac{a \xi}{1+b \xi}
$$

where $R$ is the significant runup, $H$ is the incident significant wave height, and $\xi$ is computed using $H_{m 0}$ and $T_{p}$. Here $a$ and $b$ are empirical coefficients for varied armor.

Relations for computing wave height in shallow water were given. Although Ahrens subsequently updated the equations for both structures and beaches (e.g., Ahrens and Seelig 1996, Ahrens et al. 1993), the ACES program was not updated. Application of the ACES model is uncertain because the documentation is not very clear on the parameter statistics. However, an evaluation of the ACES program showed lower skill than the equations discussed above for structures and beaches.

Runup 2.0 is the computer program recommended by FEMA for use in Flood Insurance Studies (FEMA 1981, 1991). The program is based on the empirical equations of Stoa (1978) for a wide variety of slope configurations and wave and water level conditions. Stoa used small-scale regular wave laboratory experiments to develop the empirical equations. The experiments did not include any of the modern wave generation capabilities, such as active wave absorption and second order correction for spurious bound waves. Because the Stoa tests included setup, the Runup 2.0 runup estimate also includes setup.

Stoa conducted experiments for 10 structure profiles, all with flat offshore bathymetry and relatively deep water directly offshore of the structure. So, the wave is assumed to break on the structure rather than in the nearshore zone. Ten empirical curve sets for runup prediction were developed for the 10 structure profiles and the program interpolates or extrapolates to determine runup for input conditions. If the structure profile matches Stoa's, then the calculation uses one of the digitized Stoa curves. However, if there is no match, then the composite slope method of Saville (1958) is used. This method extends runup estimates from simple structure geometries to more complex profiles. The method defines a uniform slope that provides an equivalent runup to a complex profile. A number of other adjustments are made within Runup 2.0 including corrections for depth-limited breaking, slope roughness, and scale effects.

Runup 2.0 outputs mean runup representative of regular waves. For FIS, this statistic is converted to $R_{2 \%}=2.2 * \bar{R}$ assuming Rayleigh distributed runups. Table 3 gives the error statistics and skill scores for Runup 2.0 predictions for several data sets. The skill is low because the physical processes are not well represented by the regular-wave based empirical model.

\begin{tabular}{|l|l|l|l|}
\hline \multicolumn{4}{|l|}{ Table 3. Error Statistics and Skill Scores for Runup 2.0 Predictions } \\
\hline & Mase Data & Van Gent Data & Stockdon Data \\
\hline Dimensional RMS Error $(\mathrm{m})$ & 0.03 & 0.13 & 1.04 \\
\hline Bias $(\mathrm{m})$ & -0.02 & 0.05 & -0.84 \\
\hline Nondimensional RMS Error & 0.36 & 0.80 & 0.62 \\
\hline Standard Deviation of Errors $(\mathrm{m})$ & 0.02 & 0.13 & 0.60 \\
\hline Scatter Index & 0.21 & 0.54 & 0.41 \\
\hline Normalized RMS Error Performance & -1.57 & 0.48 & 0.35 \\
\hline Normalized Bias Performance & -0.92 & 0.81 & 0.47 \\
\hline Normalized SI Performance & 0.79 & 0.46 & 0.59 \\
\hline Summary Performance & -0.57 & 0.58 & 0.47 \\
\hline
\end{tabular}

\section{WAVE TRANSFORMATION NUMERICAL MODELS THAT INCLUDE SETUP AND RUNUP}

The nearshore and swash zone consist of spatially varying bathymetry and topography that impact the incident wave climate and runup. Barred-beach and dune conditions are common and usually consist of complex bathymetry from offshore to the landward extent of the dune. During the most extreme storms, there may be significant morphological change and overtopping and erosion of the dune. Empirical equations based on limited experiments using impermeable smooth uniform slopes may not yield accurate solutions in many cases.

Several hydrodynamic models for modeling transects are in wide use and they generally fall into two categories: phase-averaged or time-averaged and phase-resolving. Phase-averaged cross-shore models, such as CSHORE, have been widely discussed in the literature (Kobayashi 1997, 2009). The primary advantage of this class of models is that they run very quickly and are very stable. The disadvantage is that they do not model the detailed transformation of individual waves so they contain 
more empiricism than phase-resolving models. An example is modeling both incident and infragravity components of a spectrum.

Phase-resolving models based on the Boussinesq equations have also gained recent popularity for practical application. The primary advantage of the Boussinesq-based models is that they capture the wave-to-wave physics and so can, in some cases, model the details of the spectral wave transformation including infragravity wave contributions. However, surfzone infragravity wave generation, trapped edge waves and other related physical processes may still not be modeled. In addition, offshore wave hindcasts often do not typically include information on bound long waves. In this case, it is unlikely that any wave model can adequately resolve the infragravity dominated components of wave runup, particularly for regional flood inundation studies where thousands of transects must be modeled. A disadvantage of Boussinesq-based models is that they require significantly more resources than phaseaveraged models and are less stable. So, for regional inundation studies where thousands of transects are modeled for hundreds of storms, detailed phase-resolving modeling for all transects and all storms may not be practical at this time.

Existing numerical models can provide consistent prediction of runup from steep to shallow slopes, including structure/beach porosity and roughness, and account for complex nearshore processes on irregular bathymetry. CSHORE has the option of including morphology change, bottom porosity, and many other complex nearshore processes. CSHORE runs extremely fast - a few seconds per storm per transect is typical. It is also very stable. A horizontally two-dimensional version of CSHORE is called C2SHORE. The programs have been validated for limited data sets as described in the many references (see Johnson et al. 2011, for validation to storm-induced morphology change data sets).

CSHORE is described in Kobayashi (1997, 2009), Pietropaolo et al. (2012), and Melby (2012) and that discussion will not be repeated herein. The model solves the time-averaged continuity, momentum, and energy equations in the region that is always wet and separately for the wet-dry region. Runup is solved as a probabilistic estimate along a runup wire in the wet-dry region assuming runups to be Rayleigh distributed. $R_{2 \%}$ is computed from this distribution.

CSHORE has a large number of options including moveable or fixed bed, roller effects, empirical breaker ratio parameter, runup wire height, and bottom friction factor. In general, the model is not very sensitive to the breaker ratio parameter or the bottom friction factor. The breaker ratio $\gamma_{c}$ parameter is typically in the range of $0.6-0.8$ with 0.7 being generally used with success herein. The bottom friction factor is less certain but values taken directly from the literature proved satisfactory for this study (e.g., Hughes 1995, Kobayashi 1999). The details of the modeling are discussed in Melby (2012). For this study, for the structure modeling, roller and wave-current interaction were turned off whereas they were turned on for beach modeling. For structures, $\gamma_{c}=0.7$ and $f=0.02$ while for beaches, $\gamma_{c}=0.8$ and $f=0.002$. For beaches, the runup wire height (RWH) was $1.5 \mathrm{~cm}$, except for Agate and SandyDuck where $\mathrm{RWH}=0.5 \mathrm{~cm}$.

Input wave conditions for CSHORE were those on the flat part of the flume for Mase and van Gent experiments and those just outside the surf zone for the beach studies. Peak wave period, $T_{p}$, was used as input to CSHORE. Further, root-mean-square wave height, $H_{r m s}$, was used and was computed as $H_{m 0} / 1.41421$ assuming Rayleigh distributed wave heights outside the surf zone. For the beach experiments, waves were measured at varying locations just outside the surf zone. Stockdon transformed these wave conditions to deep water using linear shoaling. Only the deep water wave conditions were provided to us for this study. For the present analysis, these offshore wave conditions were transformed from deep water to a depth of $8 \mathrm{~m}$ using linear wave theory and the $8 \mathrm{~m}$ depth conditions were used as input to CSHORE.

The profiles were time-averaged over the duration of the beach experiments. Each profile was extended to elevation $+4 \mathrm{~m}$ on the shoreward end and to $-8 \mathrm{~m}$ on the seaward end using the average swash and offshore slopes, respectively. Note that the Oregon profiles were estimated offshore and assumed linear. For the beach experiment analysis, the measured water levels throughout each experiment were obtained from the NOAA COOPS web site (http://tidesandcurrents.noaa.gov).

Figures 8 - 11 show measured versus CSHORE computed $R_{2 \%} / H_{m 0}$. Each figure shows a solid line for perfect agreement and 20 percent error as dashed lines. Figure 8 shows the relative runup comparison with van Gent data and Figure 9 shows the comparison for the Mase data. The runup is normalized by the wave height at the toe of the slope in relatively deep water. These two figures illustrate that CSHORE predicts $R_{2}$ well for smooth structures with nearly all of the predictions within 20 percent error and little bias. Some bias on the high side is observed in the higher relative runup in van Gent data. 

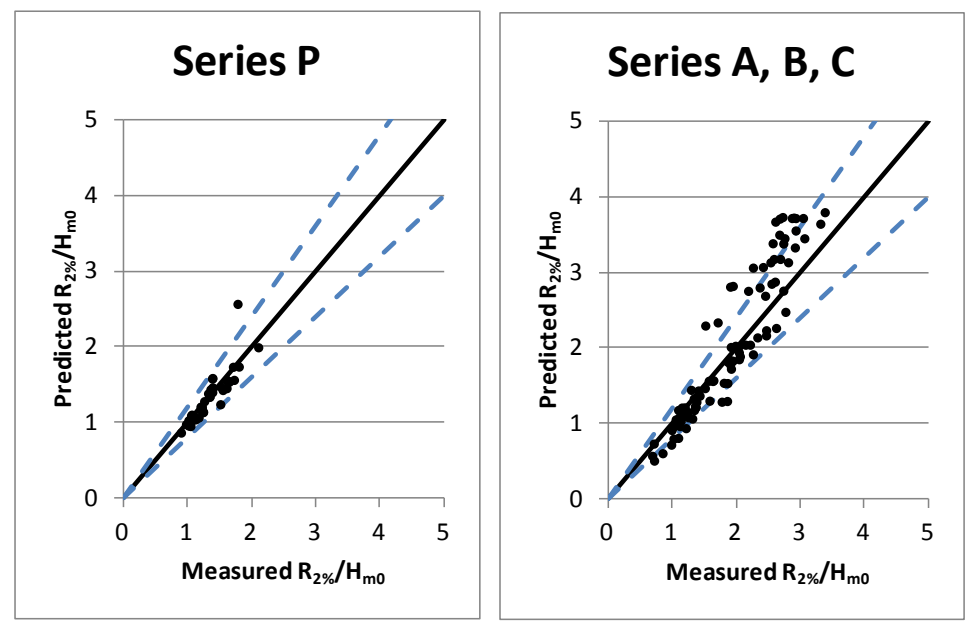

Figure 8. CSHORE predicted relative runup versus van Gent measurements. Solid black line is equality and dashed lines are the 20 percent error.

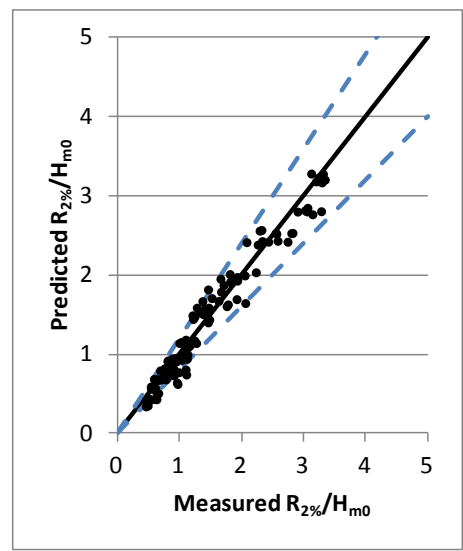

Figure 9. CSHORE predicted relative runup versus Mase measurements. Solid black line is equality and dashed lines are the 20 percent error.

Figures 10 - 11 show CSHORE prediction of relative runup compared to Stockdon beach data. Here, runup is normalized by wave height in $8 \mathrm{~m}$ depth. The sites are grouped where predictions were similar in bias and scatter. Figure 10 shows Delilah (Duck 1990), Duck 1994, San Onofre, and Scripps. The skill of CSHORE for these experiments was surprisingly similar with little bias and a reasonable level of overall skill, particularly considering there was no tuning of the model to match these measurements and only average beach profiles and nearby water level data were available. Also, measurement and analysis of wave runup, incident waves, and bathymetry were complex for these experiments, spanning nearly two decades when technology was changing rapidly and varying from site to site. Because the conditions were generally not stormy, the waves and runup were often relatively small, producing more relative scatter that would not be significant for flood hazard. Finally, as stated earlier, Scripps data were infragravity-dominated. Given these issues, it is surprising that prediction skill for data from disparate sites on different coasts would be similar. Although the largest error is nearly a factor of two, the predictions show skill similar to the empirical equations that were specifically tuned for these data sets.

Figure 11 (left) shows relative runup predictions for Duck 1982 and SandyDuck experiments while Figure 11 (right) shows relative runup predictions for Gleneden, OR, and Agate, OR. Here we see much more scatter than is shown in Figure 10, particularly for higher relative runup. Figure 11 (left) shows more scatter than Figure 10 and a few outliers but reasonable overall prediction. Comparison of the modified Mase equation with Duck 1982 and SandyDuck data in Table 4 also shows lower skill than other incident-dominated sites suggesting that poor prediction for several data points is partly due to uncertainty in the data. Figure 11 (right) shows that CSHORE has poor skill for the northwest Pacific coast. The CSHORE model over-predicted relative runup for some cases. Uncertainty in 
nearshore bathymetry and water levels for these sites adds significant uncertainty to the data. So model predictions were not expected to be accurate for these sites. It is also likely that the CSHORE model provides poor prediction of infragravity-dominated runup on dissipative beaches. For these cases, a formulation specific for dissipative beaches, like Equation 19, may be required. The large uncertainty is also a result of relatively small incident waves and resulting small runup values. It is expected that CSHORE runup predictions for storm conditions corresponding to higher flood hazard where a higher water level reaches a steeper beach face and runup is dominated by incident wave conditions would be more accurate with accuracy represented by Figure 10.

Table 4 summarizes the skill of CSHORE for predicting runup on structures as shown in Figures 8 - 9. Table 5 summarizes the skill of CSHORE for runup on beaches as shown in Figures $10-11$.

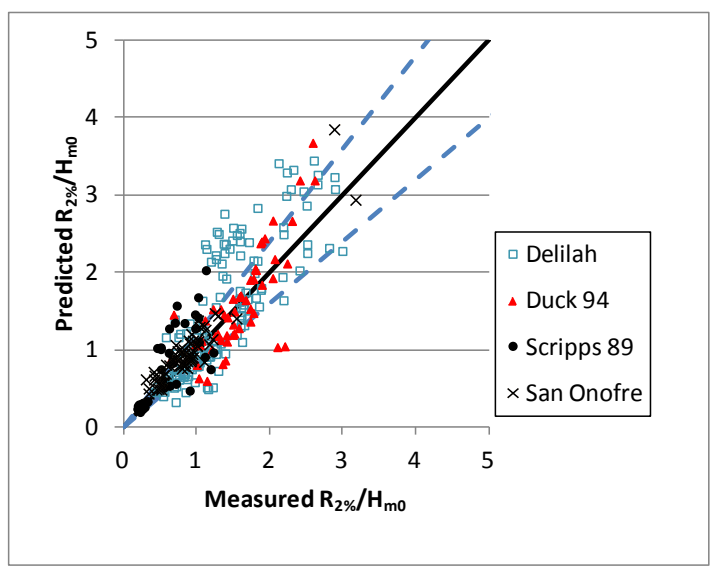

Figure 10. CSHORE predicted runup versus measured runup during Duck 1990, Duck 1994, Scripps, and San Onofre experiments. Solid black line is equality and dashed lines are the 20 percent error.
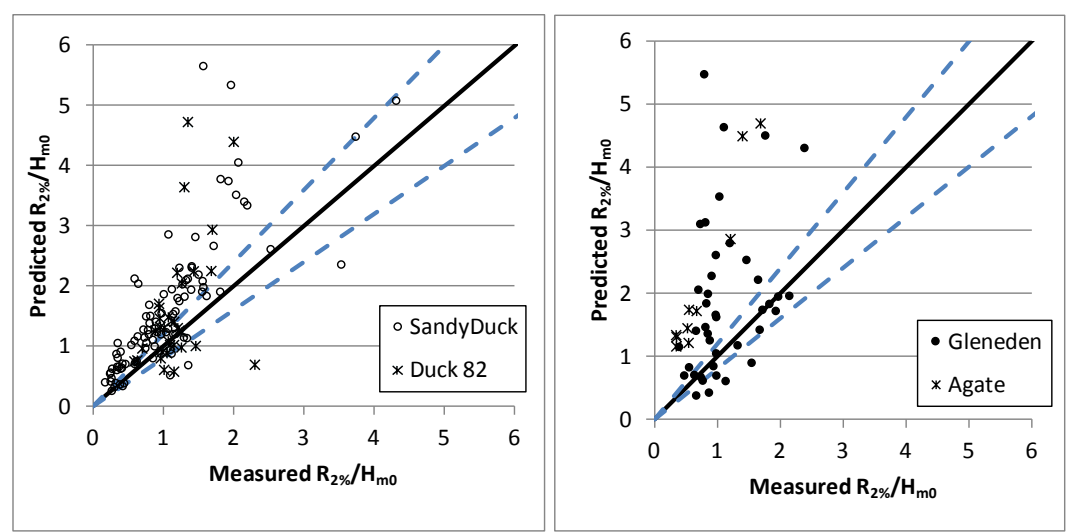

Figure 11. CSHORE predicted runup versus measured during Duck 1982 and SandyDuck experiments on left and Gleneden and Agate on right.

\begin{tabular}{|l|c|c|c|}
\hline Table 4. Error statistics and skill scores for CSHORE predictions of runup on structures. \\
\hline & Mase Data & $\begin{array}{l}\text { Van Gent Data } \\
\text { Series P }\end{array}$ & $\begin{array}{l}\text { Van Gent Data } \\
\text { Series A, B, C }\end{array}$ \\
\hline $\mathrm{N}$ & 120 & 40 & 97 \\
\hline Dimensional RMS Error (m) & 0.03 & 0.64 & 0.06 \\
\hline Bias (m) & 0.00 & -0.02 & 0.02 \\
\hline Nondimensional RMS Error & 0.13 & 0.09 & 0.19 \\
\hline Standard Deviation of Errors (m) & 0.01 & 0.65 & 0.07 \\
\hline Scatter Index & 0.11 & 0.20 & 0.11 \\
\hline Normalized RMS Error Performance & 0.90 & 0.45 & 0.79 \\
\hline Normalized Bias Performance & 0.99 & 0.98 & 0.94 \\
\hline Normalized SI Performance & 0.89 & 0.80 & 0.89 \\
\hline Summary Performance & 0.92 & 0.74 & 0.87 \\
\hline
\end{tabular}




\begin{tabular}{|c|c|c|c|}
\hline & Group 1 & Group 2 & Group 3 \\
\hline $\mathrm{N}$ & 290 & 130 & 56 \\
\hline Dimensional RMS Error (m) & 0.41 & 0.99 & 3.08 \\
\hline Bias (m) & 0.09 & 0.64 & 1.97 \\
\hline Nondimensional RMS Error $\mathrm{e}_{\mathrm{rms}}$ & 0.37 & 0.94 & 1.83 \\
\hline Standard Deviation of Errors $(\mathrm{m})$ & 0.41 & 0.76 & 2.39 \\
\hline Scatter Index & 0.28 & 0.55 & 1.42 \\
\hline Normalized RMS Error Performance & 0.74 & 0.34 & -0.77 \\
\hline Normalized Bias Performance & 0.95 & 0.57 & -0.13 \\
\hline Normalized SI Performance & 0.72 & 0.45 & -0.42 \\
\hline Summary Performance & 0.80 & 0.46 & -0.44 \\
\hline
\end{tabular}

The results summarized above suggest that CSHORE can predict runup with a high degree of skill over a broad range of wave and nearshore profile situations for storm conditions where there is a flood hazard. For the most part, the skill is comparable to empirical models that were tuned to the data. There were areas of weakness with the model though. In particular, CSHORE is not expected to predict runup well for conditions where infragravity conditions dominate, particularly on gently-sloping dissipative beaches that are typical of the northwest Pacific coast. Further research is required in this area.

\section{CONCLUSIONS}

The study goal was to establish several benchmark wave runup data sets and evaluate the available tools for predicting wave runup for flood hazard assessment. Benchmark data covered a range of shoreline conditions including sandy beaches on the Pacific and Atlantic coasts, impermeable smooth structures with uniform slopes from 1:30 to 1:5, impermeable structures with steep uniform and compound slopes (clay earthen grass-covered levees), impermeable stone-armored structures (levees and revetments), and permeable stone-armored structures (breakwaters). The beach data sets spanned the range of dissipative to reflective beaches. The structure data sets encompass a wide range of wave and water level conditions from deep water at the slope toe to shallow water with a wide surf zone. The laboratory data sets were limited to data that were carefully obtained using modern wave generation and wave measurement techniques. The data set from van Gent included full scale and small scale data and included active wave absorption, second order wave correction, and incident and reflected wave resolution.

For most shoreline conditions, CSHORE can be used to predict wave runup. This includes coastal structures and beaches. CSHORE also can be used to predict cross-shore beach morphology change where important. In addition, CSHORE can be used to predict wave overtopping of structures and dunes, although that was not analyzed in this report. CSHORE is not likely to predict wave runup on infragravity-dominated dissipative beaches well. For these cases, it is recommended that one of the recommended empirical equations for beaches be used, as discussed below.

For structures, the EurOtop equation showed good skill. For beaches where CSHORE is not applicable, or the results are questioned, or if there is a desire to have an independent prediction for comparison, one of the empirical beach runup equations described herein can be used. The Stockdon and modified Mase equations showed similar skill.

Integral, energy-based wave parameters, such as $H_{m 0}$ and $T_{m-1,0}$, are more stable than their nonintegral counterparts $\left(H_{1 / 3}, T_{p}, T_{m}\right)$ during wave transformation as a result of energy conservation. As discussed herein, $T_{p}$ becomes very uncertain in the surf zone as the wave energy density spectrum deforms. So empirical equations based on integral wave parameters, such as the van Gent equation, tend to be better generalized and have more skill. Also, wave transformation models, such as CSHORE and those based on the Boussinesq equations, tend to show more skill across the wide range of possible shoreline conditions than empirical equations partly because they take into account spectral wave transformation and wave breaking across varied bathymetry. Empirical models based on deep-water wave conditions are not very sensitive to the choice of integral or non-integral wave parameters because both are stable in deep water. However, these models will yield significant uncertainty in application to shallow water conditions with varied bathymetry. The recommendations above reflect this. 


\section{REFERENCES}

Ahrens, J.P. 1981. Irregular wave runup on smooth slopes, CETA No. 81-17, U.S. Army Corps of Engineers, Coastal Engineering Research Center, Ft. Belvoir, VA.

Ahrens, J.P., and B.L. McCartney. 1975. Wave period effect on the stability of riprap. Proc. Civil Engineering in the Oceans/III, ASCE, Reston, VA, 1019-1034.

Ahrens, J.P., and W.N. Seelig. 1996. Wave runup on beaches. Proc. 25th Intl. Conf. on Coastal Engrg, Orlando, ASCE, 981-993.

Ahrens, J. P., and M.F. Titus. 1985. Wave runup formulas for smooth slopes. J. Wtrwy., Port, Coastal, and Oc. Engrg., Vol. III, No. 1, ASCE, 128-133.

Ahrens, J.P., W.N. Seelig, D.L. Ward, and W. Allsop. 1993. Wave runup on and wave reflection from coastal structures. Proc. of Ocean Wave Measurement and Analysis (Waves '93) Conf. ASCE, 489-502.

Battjes, J.A. 1974a. Surf similarity. Proc. 14th Intl. Coastal Engrg. Conf., vol. 1. ASCE, 466-480. Battjes, J.A. 1974b. Computation of set-up, longshore currents, run-up and overtopping due to wind-generated waves. Report 74-2, Committee on Hydraulics, Department of Civil Engineering, Delft University of Technology, Delft, The Netherlands.

Coastal Engineering Manual. 2002. US Army Engineer R\&D Center, Coastal and Hydraulics Laboratory, Vicksburg, MS.

De Waal, J. P., and J.W. van der Meer. 1992. Wave runup and overtopping on coastal structures. Proc. 23rd Intl. Coastal Engrg. Conf., ASCE, 2, 1758-1771.

EurOtop. 2007. Wave Overtopping of Sea Defences and Related Structures: Assessment Manual.

Environmental Agency, UK. www.overtopping-manual.com.

FEMA. 1981. Manual for Wave Runup Analaysis, Coastal Flood Insurance Studies. Stone and Webster Engrg. Corp., Boston, pp. 96.

FEMA. 1991. Investigation and Improvement of Capabilities for the FEMA Wave Runup Model.

FEMA, Washington, DC., Prepared by Dewberry and Davis, Inc., pp. 188.

Guza, R.T, and E.B. Thornton. 1982. Swash oscillations on a natural beach. J. Geoph. Res. 87, No.

C1, American Geophysical Union. 483-491.

Holland, K.T. and R.A. Holman. 1999. Wavenumber-frequency structure of infragravity swash motions. J. Geoph. Res. 104, No. C6, American Geophysical Union. 13,479-13,488.

Holman, R.A. 1986. Extreme value statistics for wave runup on a natural beach. Coastal Engrg., 9(6). Elsevier, 527-544.

Hughes, M.G. 1995. Friction factors in wave uprush. J. of Coastal Res. 11(4), Coastal Ed. and Res. Found., Inc., 1089-1098.

Hunt, I.A. 1959. Design of seawalls and breakwaters. J. of Waterways and Harbours Division, ASCE 85 (WW3), 123-152.

Iribarren, C.R., and C. Nogales. 1949. Protection des Ports. XVIIth International Navigation

Congress, Section II, Communication. 31-80.

Jiabao, Z. 1993. Effect of wave groups on wave run-up. J. of Coastal Res., 9(4), Coastal Ed. and Res. Found., Inc., 1110-1114.

Johnson, B.D., N. Kobayashi, and M.B. Gravens. 2011. Cross-Shore numerical model CSHORE for waves, currents, sediment transport and beach profile evolution. ERDC/CHL Technical Report, in press,U.S. Army Engineer R\&D Center, Vicksburg, MS.

Kobayashi, N. 1997. Wave runup and overtopping on beaches and coastal structures. Research Report No. CACR-97-09, Center for Applied Coastal Research, University of Delaware.

Kobayashi, N. 1999. Wave runup and overtopping on beaches and coastal structures. Advances in Coastal and Ocean Engrg., Vol. 5, World Scientific, Singapore, 95-154.

Kobayashi, N. 2009. Documentation of cross-shore numerical model CSHORE. Research Report

No. CACR-09-06, Center for Applied Coastal Research, University of Delaware.

Leenknecht, D. A., A.R. Sherlock, and A. Szuwalski. 1995. Automated tools for coastal engineering. J. of Coastal Res., 11(4), Coastal Ed. and Res. Found., Inc., 1108-1124.

Longuet-Higgins, M.S., and R.W. Stewart. 1964. Radiation stresses in water waves: a physical discussion, with applications. Deep-Sea Research, 11. Pergamon Press, Great Britain, 529-562.

Longuet-Higgins, M.S., and R.W. Stewart. 1962. Radiation stress and mass transport in gravity waves with application to 'surf beats'. J. Fluid Mech. 13, 481-504. 
Madsen, P.A., H.A. Schiaffer, and O.R. Sorensen. 1997a. Surf zone dynamics simulated by a Boussinesq type model. Part I: Model description and cross-shore motion of regular waves. Coastal Engrg. 32, Elsevier, 255-288.

Madsen, P.A., O.R. Sorensen, and H.A. Schaffer. 1997b. Surf zone dynamics simulated by a Boussinesq type model. Part II: surf beat and swash oscillations for wave groups and irregular waves. Coastal Engrg. 32 (1997), Elsevier, 289-319.

Mase, H. 1989. Random wave runup height on gentle slope. J. Wtrwy., Port, Coastal, and Oc. Engrg., 115(5). ASCE, 649-661.

Mase, H., and Y. Iwagaki. 1984. Runup of random waves on gentle slopes. Proc. 19th Coastal Engrg. Conf., ASCE, 593-609.

Melby, J.A. 2012. Wave Runup Prediction for Flood Hazard Assessment. ERDC/CHL Technical Report in press, US Army Engineer R\&D Center, Vicksburg, MS.

Melby, J.A., N.C. Nadal-Caraballo, and B. Ebersole. 2012. Wave height and water level variability on Lake Michigan, ERDC/CHL Technical Report in press, U.S. Army Engineer R\&D Center, Vicksburg, MS.

Nielsen, P., and D.J. Hanslow. 1991. Wave runup distributions on natural beaches. J. of Coastal Res. 7(4), Coastal Ed. and Res. Found., Inc., 1139-1152

Pietropaolo, J., N. Kobayashi, and J.A. Melby. 2012. Wave runup on dikes and beaches. Proc. $33^{\text {rd }}$ ICCE, in press, Santander, Spain.

Saville Jr., T. 1958. Wave run-up on composite slopes. Proc. 6th Intl. Coastal Engrg. Conf., ASCE, 691-699.

USACE 1984. Shore Protection Manual. U.S. Army Engineer Waterways Experiment Station, 4th ed. U.S. Government Printing Office, Washington, DC.

Stockdon, H.F., R.A. Holman, P.A. Howd, and A.H. Sallenger. 2006. Empirical parameterization of setup, swash, and runup. Coastal Engrg. 53, Elsevier, 573-588.

Stoa, P.N. 1978. Reanalysis of wave runup on structures and beaches. U.S. Army Corps of Engineers Coastal Engineering Research Center, Ft. Belvoir, VA. TP 78-2.

TAW. 2002. Technical Report: Wave Runup and Wave Overtopping at Dikes. Technical Advisory Committee on Flood Defence, Delft, The Netherlands.

Van der Meer, J. W. 1988. Rock slopes and gravel beaches under wave attack. Ph.D. Dissertation, Delft Hydraulics Communication No. 396, Delft Hydraulics Laboratory, Emmeloord, The Netherlands. Van der Meer, J. W., and C.M. Stam. 1992. Wave runup on smooth and rough slopes of coastal structures. J. Wtrwy., Port, Coastal, and Oc. Engrg., ASCE, 118(5), 534-550.

Van Gent, M. 2001. Wave runup on dikes with shallow foreshores. J. Wtrwy., Port, Coastal, and Oc. Engrg., ASCE, 127(5), 254-262.

Van Gent, M. 1999a. Physical model investigations on coastal structures with shallow foreshores2D model stes on the Petten Sea Defence. Technical Report H3129, WL Delft Hydraulics, Rijkwaterstaat, pp. 85.

Van Gent, M. 1999b. Physical model investigations on coastal structures with shallow foreshores2D model tests with single and double-peaked wave energy spectra. Technical Report H3608, WL Delft Hydraulics, Rijkwaterstaat, pp. 70. 